\title{
Microsurgical treatment of basilar tip aneurysms: is it still acceptable?
}

\author{
Tratamento cirúrgico dos aneurismas do topo da artéria basilar: ainda uma opção aceitável?
} Felix Hendrik Pahl1,2, Matheus Fernandes de Oliveira ${ }^{1,2}$, José Marcus Rotta ${ }^{1}$

\begin{abstract}
Basilar tip aneurysms (BTAs) have a complex anatomy, making them difficult to treat. We describe our surgical results for BTAs. Methods: From 2004 to 2015 (12 years), a total of 25 small BTAs and two giant BTAs were treated in the Hospital do Servidor Público Estadual de São Paulo. Results: In 23 patients harboring aneurysms positioned anteriorly or straight, all aneurysms were clipped (complete exclusion in all on follow-up angiography). In two patients with posteriorly positioned aneurysms, there was residual neck. All patients submitted to surgical treatment of small aneurysms presented with late Glasgow Outcome Scale scores of 4 or 5 . Two patients with giant aneurysms died. Conclusion: Surgical treatment of these lesions may be accomplished with quite high success rates and low morbidity.
\end{abstract}

Keywords: intracranial aneurysm; therapeutics; general surgery; endovascular procedures.

\section{RESUMO}

Os aneurismas do topo da artéria basilar (BTAs) têm anatomia complexa tornando-os tecnicamente difíceis de serem tratados. Nós descrevemos nossos resultados cirúrgicos em BTAs. Métodos: De 2004 a 2015 (12 anos), foram tratados no Hospital do Servidor Público Estadual de São Paulo um total de 25 BTAs pequenos e 2 BTAs gigantes. Resultados: Nos 23 pacientes portadores de aneurismas direcionados anteriormente ou neutros, cem por cento dos aneurismas foram tratados (oclusão de 100\% na angiografia de seguimento). Em pacientes com aneurismas direcionados posteriormente (2 pacientes), houve colo residual. Todos os pacientes submetidos ao tratamento cirúrgico de pequenos aneurismas apresentaram Glasgow Outcome Scale (GOS) tardio de 4 ou 5. Nos 2 aneurismas gigantes, houve 2 casos de mortalidade (100\%). Conclusão: Em mãos experientes, o tratamento cirúrgico destas lesões pode ser realizado com taxas de sucesso bastante elevadas e baixa morbidade.

Palavras-chave: aneurisma intracraniano; terapêutica; cirurgia geral; procedimentos endovasculares.

Basilar tip aneurysms (BTAs) account for approximately $7 \%$ of all intracranial aneurysms $s^{1,2,3,5}$. They carry a higher risk of rupture than aneurysms in other locations, and are frequently wide-necked. The bifurcation angle of the basilar artery into the two posterior cerebral arteries creates a special zone of higher wall shear stress, which facilitates the formation of aneurysms. The high morbidity of BTAs is associated with the narrow space in which they occur, in an eloquent brain area and in close vicinity to perforator vessels, and to their higher incidence of subarachnoid hemorrhage (SAH), which is the presenting picture in up to $70 \%$ of cases ${ }^{6,7,8,9,10,11,12}$.

Complex anatomy makes the treatment of BTAs technically challenging, whether by open surgery or by endovascular means. Endovascular intervention is becoming the mainstay for management of these formidable aneurysms, but it has limitations, especially with large/giant or wide-necked lesions. The literature is scarce on data pertaining to the successful management of large, giant, wide-necked, and calcified/thrombosed BTAs ${ }^{11,12,13,14,15,16}$.

Several techniques for endovascular BTA treatments are available, such as Guglielmi detachable coils, stents, flow diverters, and balloons. Surgical clipping may be performed by some cranial approaches and even by endoscopic means, but carries a substantial risk of intraoperative and postoperative complications ${ }^{15,16,17,18,19,20,21,22,23,24,25,26,27}$.

We describe the surgical experience in a single center of surgical treatment of BTAs as an alternative to endovascular treatment.

\section{METHODS}

This paper describes the patient outcomes of a senior vascular neurosurgeon. Indications for neurosurgical treatment 
of BTAs were unruptured aneurysms $4 \mathrm{~mm}$ or larger and/or associated with SAH.

From 2004 to 2015 (12 years), 43 patients with BTAs were admitted to our facility, and treated neurosurgically. We retrospectively reviewed the records of these patients and analyzed relevant clinical information, including the surgical approach, complications, and outcome.

Clinical outcomes were described in terms of the Glasgow Outcome Scale (GOS).

The study was approved by the Ethics and Research Committee of HSPE.

\section{Sample profile}

Of the 43 patients, 11 were men (25\%) and 32 were women (75\%). Ages ranged from 49 to 74 years (mean, 58.5 years; standard deviation, 7.2 years).

Aneurysm sizes ranged from $4 \mathrm{~mm}$ to $30 \mathrm{~mm}$ (mean, 7.4 $\mathrm{mm})$. Thirty-nine (90\%) were classified as small $(<15 \mathrm{~mm})$, and four $(10 \%)$ were giant $(>25 \mathrm{~mm})$. Twenty-two patients presented with SAH (Table).

At presentation, all 11 patients without SAH presented with a Glasgow Coma Score (GCS) of 15. Among patients with SAH, 12 presented with a GCS of $15(75 \%)$, two with a GCS of 14 (12.5\%) and two patients with a GCS of 13 (12.5\%).

Regarding treatment modality, 27 of the 43 patients underwent microsurgical clipping; the remaining 16 patients received endovascular treatment. Among the SAH patients, 16 underwent open surgery and six were treated by endovascular means. Two giant aneurysms were treated by surgical and endovascular modalities.

\section{RESULTS}

\section{Surgical technique}

The standard technique adopted for BTAs was the pterional transsylvian approach, with or without pretemporal modification ${ }^{3}$. Pretemporal extension was adopted to provide a wider field inferiorly and medially to the temporal lobe ${ }^{3}$.

In two patients with small aneurysms situated entirely at or slightly over the dorsum sellae and positioned anteriorly or straight, a pure pterional approach was attempted, whereas in patients with high basilar bifurcation or a narrow space, pretemporal exposure was added (22 cases). In a single patient, in which the aneurysm was situated partially under the dorsum sellae, a transcavernous approach ${ }^{4}$ was used instead.

Two patients with giant aneurysms were treated by unique approaches. One underwent direct clipping during cardiac standstill, and the other was treated with occlusion of the basilar artery with bypass, which changed aneurysmal hemodynamics.

\section{Outcome}

The length of follow-up ranged from three months to 11 years (mean, 5.8 years). Successful clipping was achieved in all 23 patients harboring straight or anteriorly positioned aneurysms (complete exclusion in $100 \%$ on follow-up angiograms) (Figures 1 and 2). Conversely, both patients with posteriorly positioned aneurysms were left with a residual neck. On late follow-up, one of these two patients had aneurysm growth (Figure 3).

Twenty-five patients who underwent surgical treatment of small aneurysms achieved a late Glasgow Outcome Scale (GOS) score of 4 or 5 (Table).

Both giant aneurysms were ultimately fatal.

\section{Complications}

Among the 25 small aneurysms clipped, there was no mortality, two patients (8\%) had a morbidity, and two (8\%) remained with residual neck, both in patients with posteriorly projecting aneurysms. The morbidity of one patient consisted of a surgical site infection without meningitis, treated with antibiotics and surgical debridement; the other patient had a small midbrain infarction with cerebellar incoordination, which resolved completely within one year. Transient third nerve palsy occurred in the majority of our patients (77\%), with full recovery within six months. In only one patient was there a late full recovery after 18 months. No permanent third nerve palsy was observed.

Both patients with giant aneurysms died: one due to ventriculitis and cardiac arrest and one due to bypass obstruction and pneumonia.

\section{DISCUSSION}

Basilar artery aneurysms account for approximately 7\% of all intracranial aneurysms, and may be divided topographically into three subclasses (lower third, basilar trunk, and basilar tip aneurysms). Their higher morbidity has encouraged different surgical and endovascular approaches; nevertheless, treatment is still fraught with limitations, especially intraoperative and postoperative morbidity and, with endovascular methods, high rates of incomplete occlusion and late reopening ${ }^{1,2,3,4,5,6,7,8,9,10}$.

Several series have reported the outcomes of patients undergoing surgical or endovascular treatment of basilar aneurysms ${ }^{9,27}$.

Krisht et al. ${ }^{1,2}$, Lawton ${ }^{7}$, Shi et al. ${ }^{23}$ and Nanda et al. ${ }^{22}$ described surgical series with high levels of successful clipping, low rates of procedure-related mortality and acceptable morbidity, including vasospasm-related complications, ischemic events and transient partial or complete oculomotor palsies. Approximately $90 \%$ of patients were discharged with a GOS of 4 or 5 and, in the later follow-up, this number reached $94 \%^{1,2,7,22,23}$. 

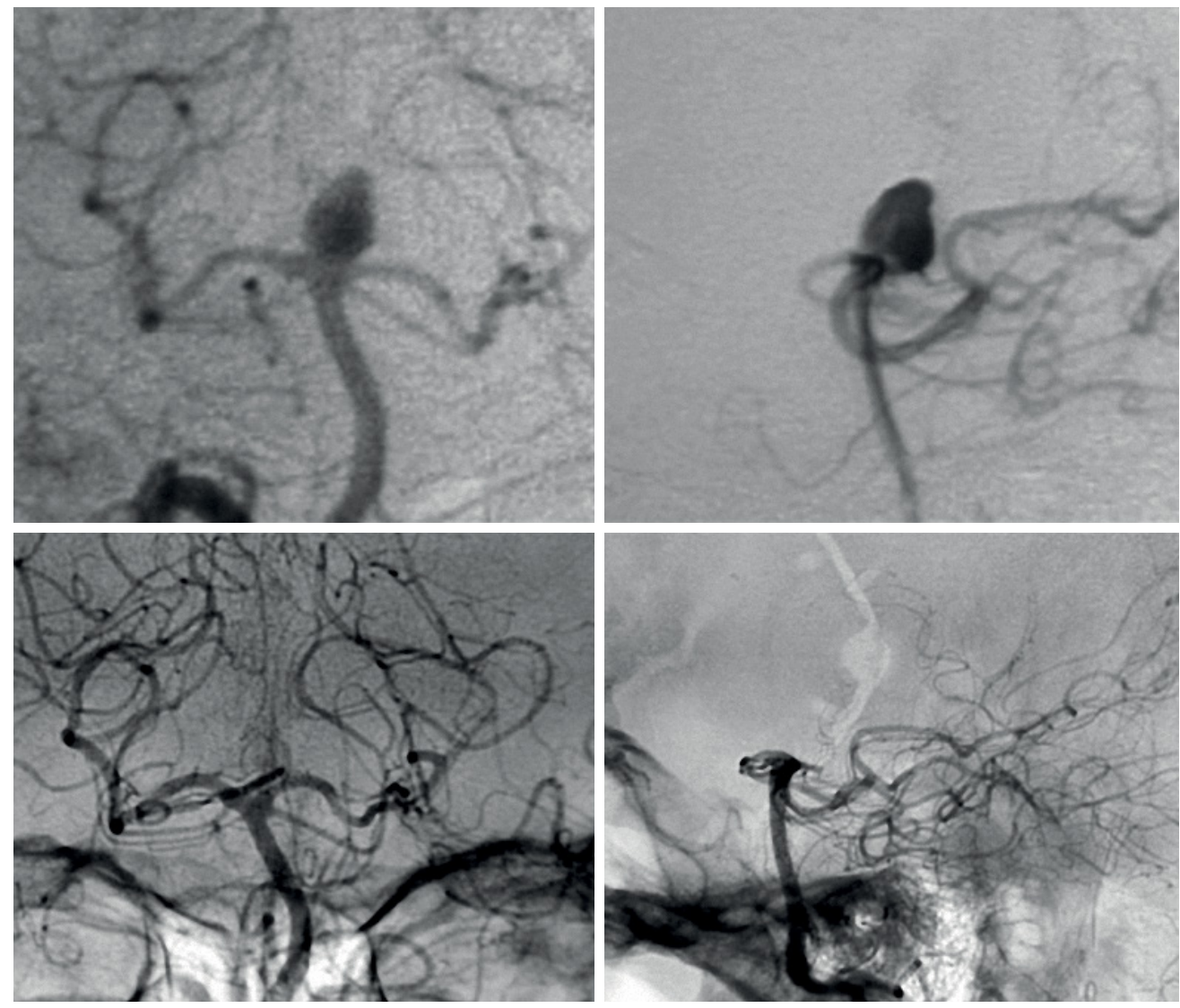

Figure 1. Pre- and postoperative angiography of a patient harboring a BTA with a straight pattern of position. Postoperative angiography with complete occlusion of aneurysm.
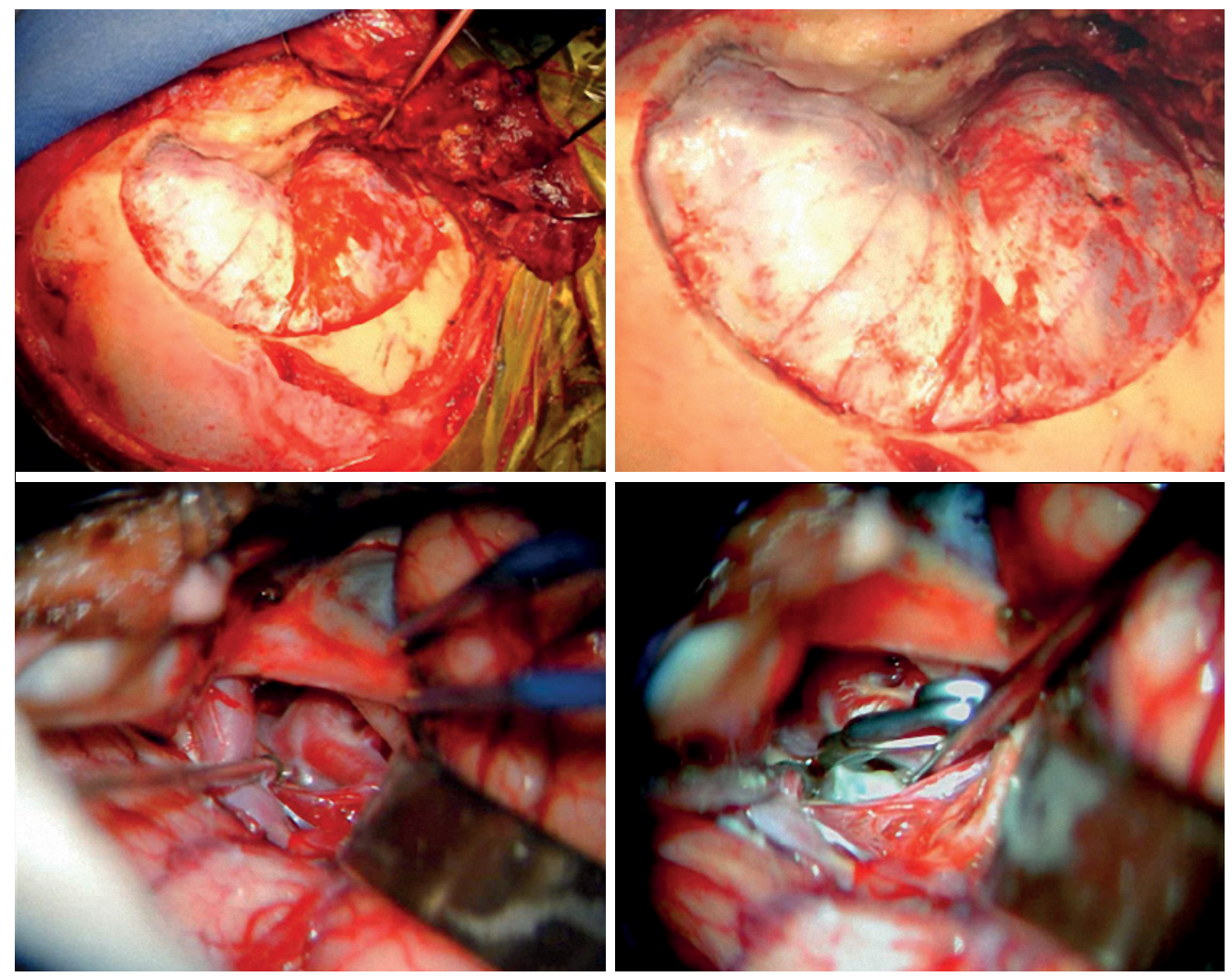

Figure 2. Surgical technique. Above, pretemporal approach. Below, aneurysm dissection and clipping. This aneurysm is the same one shown in Figure 1. 


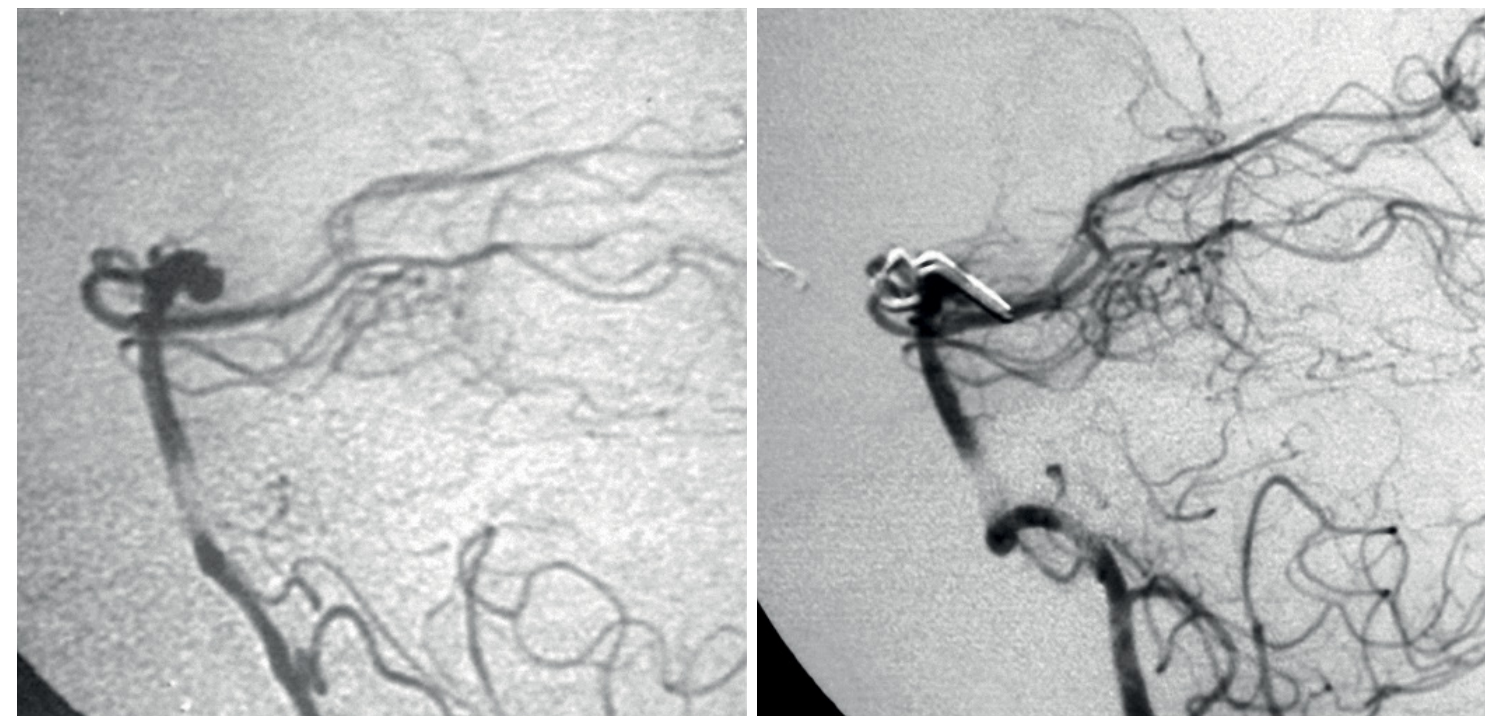

Figure 3. Pre- and postoperative angiography of a patient harboring a BTA with a posterior pattern of position. Postoperative angiography with residual neck.

Table. Sample data and surgical results.

\begin{tabular}{|c|c|c|}
\hline Parameter & $\begin{array}{c}\text { Small } \\
\text { Aneurysms } \\
(<15 \mathrm{~mm})\end{array}$ & $\begin{array}{c}\text { Large } \\
\text { Aneurysms } \\
(25 \mathrm{~mm} \text { or }>)\end{array}$ \\
\hline Number of patients & 25 & 2 \\
\hline Mean age (years) & \multicolumn{2}{|c|}{58.5} \\
\hline \multicolumn{3}{|l|}{ Aneurysmal position } \\
\hline Anterior or straight & 22 & 2 \\
\hline Posterior & 2 & \\
\hline Under the dorsum sellae & 1 & \\
\hline $\begin{array}{l}\text { Number of subarachnoid } \\
\text { hemorrhages }\end{array}$ & 16 & 0 \\
\hline Number of complications & $2(8 \%)$ & $2(100 \%)$ \\
\hline Mortality & $0 \%$ & $100 \%$ \\
\hline \multicolumn{3}{|l|}{ Aneurysmal residual neck } \\
\hline Anterior and straight & $0 \%$ & - \\
\hline Posterior & $100 \%$ & \\
\hline $\begin{array}{l}\text { Percentage of good outcome } \\
\text { (GOS } 4 \text { or } 5 \text { ) }\end{array}$ & $100 \%$ & $0 \%$ \\
\hline
\end{tabular}

In the patients who received endovascular treatment, several authors described results with different techniques, including coil alone and association with stents. Complete occlusions differ among the series, ranging from $31 \%$ to $94 \%$ of patients ${ }^{15,16}$, with risk for residual neck and need for retreatment in up to $20 \%$ of patients ${ }^{14,26,27}$. Procedure-related complications and morbidity are similar to the surgical group. Outcome scores are also very similar, ranging from 70-90\% success rates.

In summary, endovascular coil treatment of BTAs is safe, although several studies have reported relatively low complete occlusion rates (from $31.7 \%$ to $85 \%$ ) and high recurrence and retreatment rates (from $17.4 \%$ to $23 \%$ ). Coil compaction is a frequent complication of coil embolization in BTAs, occurring in $24 \%$ to $36 \%$ of cases. Complex techniques, such as double-balloon remodeling, Y-stent-assisted coil embolization, and waffle-cone stenting, have been introduced to address this issue. The use of intraluminal flow diverters in BTAs is limited by the presence of vessels in close proximity to the aneurysm neck, which would be virtually occluded by the flow diverter.

There are few studies comparing both techniques, however Sekhar et al. ${ }^{25}$ reported the results of 100 aneurysms treated in 100 patients (67\% with SAH and $33 \%$ without). In the SAH group, $62 \%$ were treated endovascularly and $38 \%$ with clipping, versus $65 \%$ by endovascular means and $35 \%$ with microsurgery in the non-SAH group (no statistical difference). Among aneurysms treated with endovascular methods, $69 \%$ in the SAH group and $75 \%$ in the non-SAH group achieved a Raymond-Roy occlusion classification of Class 1. The authors also described that there was no residual aneurysm or residual neck in patients treated surgically, with no difference in the final outcome between treatment modalities $^{25}$. They proposed that both are equally safe and effective, but the surgical approach should warrant better rates of aneurysmal exclusion and retreatment ${ }^{25}$.

\section{Analysis}

In experienced hands, quite high success rates can be achieved with the surgical treatment of basilar aneurysms.

In our sample of 25 patients with small BTAs $(<15 \mathrm{~mm})$, $100 \%$ of aneurysms were clipped (complete exclusion in $92 \%$ on follow-up angiography). One patient with a residual aneurysm neck showed recanalization during follow-up. There were no cases of rebleeding during the follow-up period. A good outcome (GOS 4-5) was achieved in all patients, and there was no mortality. 
We believe that BTAs can be treated by surgical means with acceptable morbidity and outcomes as good as those provided by endovascular treatment. On late follow-up, aneurysms treated surgically tended to exhibit a lower rate of recanalization than those treated by endovascular means. Backwardprojecting aneurysms were associated with worse outcomes and higher rates of a residual neck after clipping. Outcomes for giant aneurysms remain dismal, whether treatment is endovascular or surgical.

\section{Limitations}

Some limitations of this report should be noted. Firstly, our number of patients was small, mainly due to the low prevalence of BTAs. Also, a retrospective study is methodologically weak to be able draw strong conclusions. Finally, we did not perform a controlled evaluation with an endovascular treatment group. Although these aspects impact the inferences of the study, they do not invalidate our surgical series and respective outcomes.

\section{CONCLUSIONS}

Surgical clipping may continue to be a good option for the treatment of basilar tip aneurysms due to a higher rate of aneurysm occlusion and stability of the treatment, especially in experienced hands.

\section{ACKNOWLEDGEMENT}

The authors thank to all physicians and residents in the Neurosurgery Department in IAMSPE and DFV Neuro for their continuous support.

\section{References}

1. Krisht AF, Krayenbühl N, Sercl D, Bikmaz K, Kadri PA. Results of microsurgical clipping of 50 high complexity basilar apex aneurysms. Neurosurgery. 2007;60(2):242-50. https://doi.org/10.1227/01.NEU.0000249265.88203

2. Krisht AF, Kadri PA. Surgical clipping of complex basilar apex aneurysms: a strategy for successful outcome using the pretemporal transzygomatic transcavernous approach. Neurosurgery. 2005;56(2 Suppl):261-73.

3. Oliveira E, Tedeschi H, Siqueira MG, Peace DA. The pretemporal approach to the interpeduncular and petroclival regions. Acta Neurochir (Wien). 1995;136(3-4):204-11. https://doi.org/10.1007/BF01410627

4. Dolenc VV, Skrap M, Sustersic J, Skrbec M, Morina A. A transcavernous-transsellar approach to the basilar tip aneurysms. Br J Neurosurg. 1987;1 (2):251-9. https://doi.org/10.3109/02688698709035309

5. Lozier AP, Kim GH, Sciacca RR, Connolly ES Jr, Solomon RA. Microsurgical treatment of basilar apex aneurysms: perioperative and long-term clinical outcome. Neurosurgery. 2004;54(2):286-96. https://doi.org/10.1227/01.NEU.0000103222.13642.00

6. Lusseveld E, Brilstra EH, Nijssen PC, Rooij WJ, Sluzewski M, Tulleken CA et al. Endovascular coiling versus neurosurgical clipping in patients with a ruptured basilar tip aneurysm. J Neurol Neurosurg Psychiatry. 2002;73(5):591-3. https://doi.org/10.1136/jnnp.73.5.591

7. Lawton MT. Basilar apex aneurysms: surgical results and perspectives from an initial experience. Neurosurgery. 2002;50(1):1-10. https://doi.org/10.1097/00006123-200201000-00002

8. Sforza DM, Putman CM, Scrivano E, Lylyk P, Cebral JR. Bloodflow characteristics in a terminal basilar tip aneurysm prior to its fatal rupture. AJNR Am J Neuroradiol. 2010;31(6):1127-31. https://doi.org/10.3174/ajnr.A2021

9. Dai D, Ding YH, Kelly M, Kadirvel R, Kallmes D. Histopathological findings following pipeline embolization in a human cerebral aneurysm at the basilar tip. Interv Neuroradiol. 2016;22(2):153-7. https://doi.org/10.1177/1591019915622165

10. Chen Y, Dai D, Fang Y, Yang P, Huang Q, Zhao W et al. Endovascular treatment of ruptured large or wide-neck basilar tip aneurysms associated with moyamoya disease using the stent-assisted coil technique. J Stroke Cerebrovasc Dis. 2015;24(10):2229-35. https://doi.org/10.1016/j.jstrokecerebrovasdis.2015.05.024
11. Sheth SA, Patel NS, Ismail AF, Freeman D, Duckwiler G, Tateshima S. Treatment of wide-necked basilar tip aneurysm not amenable to Y-stenting using the PulseRider device.J Neurointerv Surg. 2016;8(9):e37. https://doi.org/10.1136/bcr-2015-011836

12. Chen Y, Dai D, Fang Y, Yang P, Huang Q, Zhao W et al. Endovascular treatment of ruptured large or wide-neck basilar tip aneurysms associated with moyamoya disease using the stent-assisted coil technique. J Stroke Cerebrovasc Dis. 2015;24(10):2229-35. https://doi.org/10.1016/j.jstrokecerebrovasdis.2015.05.024

13. Tsurumi A, Tsurumi Y, Negoro M, Tsugane S, Ryuge M, Susaki N et al. Delayed rupture of a basilar artery aneurysm treated with coils: case report and review of the literature. J Neuroradiol. 2013;40(1):54-61. https://doi.org/10.1016/j.neurad.2012.08.005

14. Chalouhi N, Jabbour P, Gonzalez LF, Dumont AS, Rosenwasser R, Starke RM et al. Safety and efficacy of endovascular treatment of basilar tip aneurysms by coiling with and without stent assistance: a review of 235 cases. Neurosurgery. 2012;71(4):785-94. https://doi.org/10.1227/NEU.0b013e318265a416

15. Peluso JP, van Rooij WJ, Sluzewski M, Beute GN. Coiling of basilar tip aneurysms: results in 154 consecutive patients with emphasis on recurrent haemorrhage and re-treatment during mid- and longterm follow-up. J Neurol Neurosurg Psychiatry. 2008;79(6):706-11. https://doi.org/10.1136/jnnp.2007.127480

16. Jin SC, Ahn JS, Kwun BD, Kwon DH. Analysis of clinical and radiological outcomes in microsurgical and endovascular treatment of basilar apex aneurysms. J Korean Neurosurg Soc. 2009;45(4):224-30. https://doi.org/10.3340/jkns.2009.45.4.224

17. Briganti F, Leone G, Marseglia M, Mariniello G, Caranci F, Brunetti A et al. Endovascular treatment of cerebral aneurysms using flow-diverter devices: A systematic review. Neuroradiol J. 2015;28(4):365-75. https://doi.org/10.1177/1971400915602803

18. Wang CB, Shi WW, Zhang GX, Lu HC, Ma J.Flow diverter treatment of posterior circulation aneurysms. A meta-analysis. Neuroradiology. 2016;58(4):428-35. https://doi.org/10.1007/s00234-016-1649-2

19. Rooij WJ, Bechan RS, Peluso JP, Sluzewski M. Endovascular treatment of intracranial aneurysms in the flow diverter era: frequency of use and results in a consecutive series of 550 treatments in a single centre. Interv Neuroradiol. 2014;20(4):428-35. https://doi.org/10.15274/NRJ-2014-10047 
20. Corns R, Zebian B, Tait MJ, Walsh D, Hampton T, Deasy N et al. Prevalence of recurrence and retreatment of ruptured intracranial aneurysms treated with endovascular coil occlusion. Br J Neurosurg. 2013;27(1):30-3. https://doi.org/10.3109/02688697.2012.701676

21. Albuquerque FC, Park MS, Abla AA, Crowley RW, Ducruet AF, McDougall CG. A reappraisal of the Pipeline embolization device for the treatment of posterior circulation aneurysms.J Neurointerv Surg. 2015;7(9):641-5. https://doi.org/10.1136/neurintsurg-2014-011340

22. Nanda A, Sonig A, Banerjee AD, Javalkar VK. Microsurgical management of basilar artery apex aneurysms: a single surgeon's experience from Louisiana State University, Shreveport. World Neurosurg. 2014;82(1-2):118-29. https://doi.org/10.1016/j.wneu.2013.06.016

23. Shi X, Qian H, Singh KC, Zhang Y, Zhou Z, Sun Y et al. Surgical management of vertebral and basilar artery aneurysms: a single center experience in 41 patients. Acta Neurochir (Wien). 2013;155(6):1087-93. https://doi.org/10.1007/s00701-013-1656-6
24. Sugiu K, Tokunaga K, Hishikawa T, Itami H, Okuma Y, Hiramatsu M, Haruma J, Date I. [Endovascular treatment for basilar tip aneurysms]. No Shinkei Geka. 2012;40(9):765-74. Japanese.

25. Sekhar LN, Tariq F, Morton RP, Ghodke B, Hallam DK, Barber J, Kim LJ. Basilar tip aneurysms: a microsurgical and endovascular contemporary series of 100 patients. Neurosurgery. 2013;72(2):284-98. https://doi.org/10.1227/NEU.0b013e3182797952

26. Eijck M, Bechan RS, Sluzewski M, Peluso JP, Roks G, Rooij WJ. Clinical and imaging follow-up of patients with coiled basilar tip aneurysms up to 20 years. AJNR Am J Neuroradiol. 2015;36(11):2108-13. https://doi.org/10.3174/ajnr.A4410

27. Ferns SP, Sprengers ME, Rooij WJ, Zwam WH, Kort GA, Velthuis BK et al. Late reopening of adequately coiled intracranial aneurysms: frequency and risk factors in 400 patients with 440 aneurysms. Stroke. 2011;42(5):1331-7. https://doi.org/10.1161/STROKEAHA.110.605790 